\title{
Composição Bromatológica, Disponibilidade de Forragem e Índice de Área Foliar de 17 Genótipos de Capim-Elefante (Pennisetum purpureum Schum.) sob Pastejo, em Campos dos Goytacazes, $\mathbf{R J}^{1}$
}

\author{
Manoel Messias Pereira da Silva ${ }^{2}$, Hernan Maldonado Vasquez ${ }^{3}$, José Fernando Coelho da \\ Silva ${ }^{4}$, Ricardo Enrique Bressan-Smith ${ }^{5}$, Eleonora D'Avila Erbesdobler ${ }^{6}$, Cézar da Silva Soares ${ }^{7}$
}

\begin{abstract}
RESUMO - O experimento foi conduzido entre outubro de 1998 e janeiro de 1999, no setor de forragicultura da Universidade Estadual do Norte Fluminense, em Campos dos Goytacazes, RJ. Foram avaliados os teores de proteína bruta, fibra em detergente neutro e fibra em detergente ácido, a produção de matéria seca da forragem disponível e o índice de área foliar de 17 genótipos de capim-elefante (Pennisetum purpureum Schum.), 15 clones de capim-elefante: CNPGL 91-19-1, CNPGL 91-10-5, CNPGL 91-27-5, CNPGL 91-02-5, CNPGL 91-01-2, CNPGL 91-13-2, CNPGL 91-25-3, CNPGL 91-10-2, CNPGL 91-02-4, CNPGL 91-11-2, CNPGL 91-34-1, CNPGL 91-27-1, CNPGL 91-28-1, CNPGL 91-06-3, CNPGL 91-17-5 e duas cultivares, MINEIRO e TAIWAN A-146, provenientes do BAGCE da EMBRAPA Gado de Leite. Os genótipos foram submetidos ao pastejo, na época das águas, por grupos de 10 a 13 vacas secas com peso vivo médio de $500 \mathrm{~kg}$, por um período de 1 a 2 dias. O delineamento experimental foi o de blocos casualizados com quatro repetições, em três ciclos de pastejo. Os genótipos CNPGL 91-01-2, CNPGL 91-10-2, CNPGL 91-25-3, CNPGL 91-10-5 e CNPGL 91-27-5 apresentaram maiores teores de proteína bruta e menores valores de fibra em detergente neutro e fibra em detergente ácido. De modo geral, a composição bromatológica foi influenciada negativamente pelo ciclo após ciclo de pastejo. Não houve diferenças na produção de matéria seca dos genótipos. Os genótipos CNPGL 91-02-5 e CNPGL 91-11-2 apresentaram IAF extremos de 7,08 e 6,67, respectivamente. Houve diferenças do primeiro para os demais ciclos de pastejo, tanto para a produção de matéria seca como para o índice de área foliar.
\end{abstract}

Palavras-chave: área foliar, ciclos de pastejo, fibra em detergente ácido, fibra em detergente neutro, produção de matéria seca, proteína bruta

\section{Chemical Composition, Available Forage and Leaf Area Index of 17 Genotypes of Elephantgrass (Pennisetum purpureum Schum.) under Grazing, at Campos dos Goytacazes, RJ}

\begin{abstract}
The assay was conducted from October 1998 to January 1999 in the cropgrass section of the Universidade Estadual do Norte Fluminense in Campos dos Goytacazes, RJ. The levels of crude protein, neutral detergent fiber, acid detergent fiber, the forage yield and the leaf area index (LAI) were evaluated in 17 genotypes of elephantgrass (Pennisetum purpureum, Schum.), fifteen new clones of elephantgrass: CNPGL 91-19-1, CNPGL 91-10-5, CNPGL 91-27-5, CNPGL 91-02-5, CNPGL 91-01-2, CNPGL 91-13-2, CNPGL 91-25-3, CNPGL 91-10-2, CNPGL 91-02-4, CNPGL 91-11-2, CNPGL 91-34-1, CNPGL 91-27-1, CNPGL 91-28-1, CNPGL 91-06-3, CNPGL 91-17-5 and two cultivars, MINEIRO and TAIWAN A-146, from the BAGCE of the Dairy Cattle Research Center - EMBRAPA. The elephantgrasses were submited to grazing, in the rainy season, by lots of 10 to 13 dry cows with average live weight of $500 \mathrm{~kg}$, during a period of 1 to 2 days. The genotypes CNPGL 91-01-2, CNPGL 91-10-2, CNPGL 91-25-3, CNPGL 91-10-5 and CNPGL 91-27-5 showed greatest percentage of crude protein, and smaller values of neutral detergent fiber and acid detergent fiber. In general, the chemical composition was negatively affected by period after period of grazing. No differences were found in the forage dry matter yield of the genotypes. The genotypes CNPGL 91-02-5 and CNPGL 91-11-2 presented utmost LAI of 7.08 and 6.67, respectively. Differences were found from the first to other grazing periods, as to dry matter production as to leaf area index.
\end{abstract}

Key Words: acid detergent fiber, crude protein, dry matter production, grazing periods, leaf area, neutral detergent fiber

\footnotetext{
${ }^{1}$ Parte do trabalho de tese de mestrado do primeiro autor, financiado com recursos da Fundação Estadual do Norte Fluminense (FENORTE).

2 Zootecnista, M.Sc., Laboratório de Zootecnia e Nutrição Animal (LZNA), Centro de Ciências e Tecnologias Agropecuárias (CCTA), Universidade Estadual do Norte Fluminense (UENF), Av. Alberto Lamêgo, 2000, Campos dos Goytacazes, RJ. CEP:28015-620. E.mail: manel@uenf.br

3 Professor Associado do LZNA/CCTA/UENF. E.mail: hernan@uenf.br

4 Professor Titular do LZNA/CCTA/UENF. E.mail: jcoelho@uenf.br

5 Professor Associado do Laboratório de Melhoramento Genético Vegetal (LMGV), CCTA/UENF. E.mail: brsmith@uenf.br

${ }^{6}$ Zootecnista, M.Sc., Laboratório de Ciências Ambientais (LCA), Centro de Biociências e Biotecnologias (CBB), UENF. E.mail: lola@uenf.br

${ }^{7}$ Zootecnista, Setor de forragicultura do LZNA/CCTA/UENF. E.mail: scezar@uenf.br
} 


\section{Introdução}

O capim-elefante (Pennisetum purpureum Schum.) apresenta elevado potencial de produção, firmando-se como uma espécie de extrema importância para manutenção de altos níveis de produtividade dentro da produção animal, tendo recebido especial atenção em sistemas de pastejo rotacionado para intensificação da produção leiteira (Pereira et al., 1997), uma das principais atividades da pecuária na região Norte Fluminense. Entretanto, ainda existem inúmeras limitações para o uso desta tecnologia. Entre elas, estão as caracterizações das cultivares, pois, apesar do grande número de cultivares existentes, a maioria das informações disponíveis refere-se ao desempenho dessa espécie sob cortes (Botrel et al., 1994), levando ao uso indevido de cultivares de corte em pastejo.

A partir da clonagem de progênies selecionadas da espécie efetuada pelos bancos de germoplasma, pode-se avaliar e selecionar os clones resultantes em diversas condições edafoclimáticas, obtendose novas cultivares tanto para corte como para pastejo. A composição bromatológica, entre os fatores de seleção, reflete o valor nutritivo da planta forrageira e o consumo animal, determinando a produtividade do rebanho. Segundo Veiga (1994), a alta produtividade desta gramínea está positivamente relacionada ao seu índice de área foliar (IAF). No entanto, o IAF varia dentro da espécie, podendo ser influenciado pelos fatores externos de produção (Gomide, 1973). Assim, tornam-se imprescindíveis o estudo e a seleção de cultivares mais promissoras quanto ao seu valor nutritivo e a sua produtividade. Este trabalho teve por objetivo avaliar genótipos de capim-elefante mais adaptados às condições locais do Norte Fluminense, quanto aos teores de fibra e proteína, à produção de forragem e ao IAF, em três ciclos de pastejo.

\section{Material e Métodos}

O experimento foi conduzido no Setor de Forragicultura do Laboratório de Zootecnia e Nutrição Animal (LZNA), do Centro de Ciências e Tecnologias Agropecuárias (CCTA), da Universidade Estadual do Norte Fluminense (UENF), localizado nas dependências do Colégio Agrícola Estadual "Antônio Sarlo" no município de Campos dos Goytacazes, RJ.O campo experimental está situado a $21^{\circ} 44^{\prime} 47^{\prime \prime}$ Lat. S. e $41^{\circ} 18^{\prime} 24^{\prime \prime}$ Long. O., a 12 m de altitude (Ometto, 1981). A precipitação anual da região ficou em torno de $1020 \mathrm{~mm}$ e a temperatura média mensal, em torno de $23,2^{\circ} \mathrm{C}$, com mínima de $20,2^{\circ} \mathrm{C}$ em julho e máxima de $26,2^{\circ} \mathrm{C}$ em janeiro. A área de cultivo dos genótipos é um segmento do tipo Terraço e o solo classificado como um Latossolo Amarelo distrófico, de textura arenosa. A análise química das amostras do solo, realizada antes do período experimental, foi feita pelo Laboratório de Análises de Solo do Departamento de Produção Vegetal, da Fundação Norte Fluminense de Desenvolvimento Regional (Fundenor), no município de Campos dos Goytacazes- RJ e os resultados estão apresentados no Tabela 1.

Os genótipos foram estabelecidos no verão de 1995 , em parcelas de $17,5 \mathrm{~m}^{2}$ do solo convencionalmente preparado, corrigido e fertilizado. As mudas de frações de colmos de capim-elefante foram plantadas em sulcos espaçados em 0,50 $\mathrm{m}$ dentro da parcela (5 linhas de $5 \mathrm{~m}$ por parcela), constituindo uma área experimental de cerca de $2250 \mathrm{~m}^{2}$ formada por blocos de 17 parcelas com espaçamentos de $1,5 \mathrm{~m}$ entre parcelas e 3,0 m entre blocos. Assim, adotou-se o delineamento em blocos ao acaso, com 4 repetições. Dezessete genótipos de capim-elefante foram avaliados, sendo 15 novos clones (híbridos intraespecíficos) de capim-elefante: CNPGL 91-19-1, CNPGL 91-10-5, CNPGL 91-27-5, CNPGL 91-02-5,

Tabela 1 - Análise química do solo da área experimental, na camada de $0-0,20 \mathrm{~m}$ de profundidade

Table 1 - Chemical analysis of the soil of the experimental area, in layer of $0-0.20 \mathrm{~m}$ depth

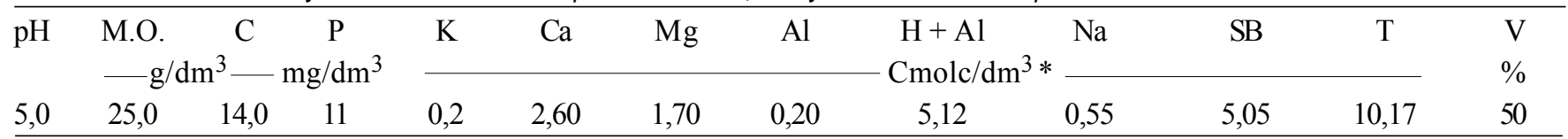

${ }^{*}$ Centimol carga $/ \mathrm{dm}^{3}$ de solo.

${ }^{*}$ Centmol charge/ $\mathrm{dm}^{3}$ of soil.

R. Bras. Zootec., v.31, n.1, p.313-320, 2002 (suplemento) 
CNPGL 91-01-2, CNPGL 91-13-2, CNPGL 91-25-3, CNPGL 91-10-2, CNPGL 91-02-4, CNPGL 91-11-2, CNPGL 91-34-1, CNPGL 91-27-1, CNPGL 91-28-1, CNPGL 91-06-3, CNPGL 91-17-5 e duas cultivares testemunhas de capim-elefante, Mineiro \& Taiwan A-146, provenientes do Banco Ativo de Germoplasma de Capim-Elefante (BAGCE) da EMBRAPA Gado de Leite. Foi utilizado o sistema de pastejo rotativo, com lotação variável de vacas secas da raça Gir (tipo P.O.), em três ciclos de pastejo (de 36 dias), de acordo com a disponibilidade de forragem, com 13 vacas no primeiro ciclo e 10 vacas nos segundo e terceiro ciclos. O período experimental ocorreu na estação chuvosa, de outubro de 1998 a janeiro de 1999. No final de cada ciclo de pastejo, a área experimental recebeu adubação de cobertura, baseada em $100 \mathrm{~kg} / \mathrm{ha}$ de $\mathrm{P}_{2} \mathrm{O}_{5}, 200 \mathrm{~kg} / \mathrm{ha}$ de $\mathrm{K}_{2} \mathrm{O}$ e $100 \mathrm{~kg} / \mathrm{ha} \mathrm{de} \mathrm{N}$.

Com aproximadamente $24 \mathrm{~h}$ do início de cada pastejo, amostras dos genótipos foram cortadas e coletadas a partir de um quadrado de 0,50 $\mathrm{m}\left(0,25 \mathrm{~m}^{2}\right)$ lançado em cada parcela, em um extrato a $0,80 \mathrm{~m}$ acima do solo. As coletas das amostras ocorreram sempre na estação chuvosa, sendo a $1^{\mathrm{a}}$ coleta em $28 / 10 / 98$, a $2^{\mathrm{a}}$ coleta em 11/12/98 e a $3^{\text {a }}$ coleta em 14/01/99.

Amostras com cerca de $500 \mathrm{~g}$ de forragem foram coletadas dentro da área útil de cada parcela, acondicionadas em sacos de papel, pesadas, identificadas e levadas ao Laboratório de Zootecnia e Nutrição Animal (LZNA), no CCTA/UENF, para as posteriores análises químico-bromatológicas de proteína bruta (PB), fibra em detergente neutro (FDN) e fibra em detergente ácido (FDA), segundo as metodologias descritas por Silva (1990). A disponibilidade de forragem foi determinada pela produção de matéria seca (PMS) dos genótipos estimada pela coleta das amostras (na área útil de cada parcela), que, após pesadas no campo, foram levadas ao LZNA, onde foram secas em estufa e novamente pesadas, de acordo com a metodologia descrita por Silva (1990), para obtenção do teor de matéria seca das amostras. Os valores da PMS obtidos na área útil foram, então, extrapolados para produção por hectare.

As amostras para determinação do IAF, acondicionadas em sacos plásticos, foram mantidas sob refrigeração a $5^{\circ} \mathrm{C}$ e levadas ao setor de Fisiologia Vegetal do Laboratório de Melhoramento Genético Vegetal (LMGV) do Centro de Ciências e Tecnologias Agropecuárias (CCTA), onde as lâminas foliares foram destacadas dos colmos para determinação da área foliar total de cada genótipo, utilizando-se o medidor de área foliar modelo LI 3100 (Li-cor, USA). A área foliar total (lâminas verdes) presente na área útil de $0,25 \mathrm{~m}^{2}$ foi estimada por regra de três, obtida pelos pesos da matéria seca das amostras de lâmina foliar + caule e pelo peso da matéria seca do material coletado na área útil. O IAF de cada genótipo correspondeu à razão entre a sua área foliar total e a área dada pelo quadrado de amostragem.

As variáveis em estudo foram submetidas à análise estatística utilizando-se o programa SAEG (Sistema para Análises Estatísticas e Genéticas), desenvolvido pela Universidade Federal de Viçosa, MG (UFV, 1997). Foram realizadas a análise de variância e a comparação entre médias pelo teste de ScottKnott, a 5\% de probabilidade, para todas as variáveis. Os dados foram analisados de acordo com o seguinte modelo estatístico:

$$
Y_{i k j}=\mu+t_{i}+b_{j}+e_{i j}+r_{k}+r_{t i k}+e_{i k j}
$$

em que: Yikj = observação relativa à parcela que recebeu o tratamento $i$, no período k e no bloco $j$; $\mu=$ média geral; $\mathrm{ti}=$ efeito do tratamento, $\mathrm{i}=(1, \ldots$, 17); $b_{j}=$ efeito do bloco, $j=(1, \ldots, 4) ; r k=$ efeito do período, $\mathrm{k}=(1,2,3) ; \mathrm{r}_{\text {tik }}=$ efeito da interação tratamento $\mathrm{x}$ período; eij $=$ efeito do erro aleatório, normal e independente, distribuído com média 0 e variância $\sigma^{2} \mathrm{~A}$, no tratamento $\mathrm{i}$ e no bloco $\mathrm{j}$; $\mathrm{e}_{\mathrm{ikj}}=$ efeito do erro aleatório, normal e independente, distribuído com média 0 e variância $\sigma^{2} \mathrm{~B}$, no tratamento $\mathrm{i}$, no período $\mathrm{k}$ e no bloco j.

\section{Resultados e Discussão}

Foram observadas diferenças $(\mathrm{P}<0,05)$ nos teores de $\mathrm{PB}$ entre os genótipos (Tabela 2), registrando-se valores mais baixos e mais altos, respectivamente, de 9,40 (CNPGL 91-02-5) e 11, 64\% (CNPGL 91-01-2). Estes valores são semelhantes aos encontrados por Silva (1993), que obteve maior teor médio de PB, $11,6 \%$, em lâminas foliares de capim-elefante anão sob alta pressão de pastejo (3-6 kg MS/animal). Valores de PB inferiores foram observados por Olivo et al. (1992), em pastagem de capim-elefante cv. Napier, em Santa Maria (RS), que obtiveram teor médio de $8,14 \%$ em três ciclos de pastejo (de 21 dias) na época das águas. Segundo Derez (1994), o período de descanso da pastagem de capim-elefante, no pastejo rotacionado, interfere principalmente na qualidade da forragem. Este autor encontrou valores de 15,5 e 13,5\% de PB na MS de capim-elefante com 30 e 45 dias de rebrota, respectivamente. Costa (1995), 
avaliando o efeito da adubação nitrogenada em capim-elefante cv. Cameroon, em cortes com intervalos de 42 dias, encontrou teor de PB de 8,74\%, aplicando $100 \mathrm{~kg}$ de N/ha/ano. Townsend et al. (1994) encontraram teor médio de $10 \pm 2 \%$ de PB no extrato de forragem pastejada de quatro cultivares de capim-elefante, em três ciclos de pastejo de 32 dias, na época das águas, no Rio Grande do Sul.

Todos os valores de PB encontrados neste experimento estão acima dos descritos por Minson(1984), que preconizou a necessidade de ingestão de forragem com um mínimo de 6 a $8 \%$ de PB na MS para manutenção de um consumo voluntário adequado. Os níveis médios de PB obtidos neste estudo, durante os três ciclos de pastejo de 36 dias, indicam existirem diferenças no valor nutritivo dos genótipos, possibilitando a seleção dos melhores, para garantir oferta de forragem de boa qualidade aos animais em regime de pastejo.

$\mathrm{Na}$ Tabela 3 observa-se que houve diferença $(\mathrm{P}<0,05)$ nos teores médios de $\mathrm{PB}$ entre os ciclos de pastejo, registrando-se valores médios de 11,03; 10,53 e $10,36 \%$, respectivamente, para os ciclos 1,2 e 3 . O decréscimo com o suceder dos ciclos decorre do acúmulo de $\mathrm{MS}$ residual ocorrido no $1^{\circ}$ ciclo de pastejo (C1), uma vez que os perfilhos laterais surgidos após a eliminação dos meristemas apicais poderiam conter baixa porcentagem de folhas que apresentam valor nutritivo superior às hastes. Além das mudanças das características morfofisiológicas da planta sob pastejo, alguns fatores do ambiente poderiam diminuir o teor de PB de um ciclo de pastejo para outro, como a redução da umidade do solo, pela queda da pluviosidade com o decorrer dos meses, que contribui para diminuir o $\mathrm{N}$ disponível à gramínea, promovendo, assim, menor teor de PB na MS da forragem.

Os teores médios de FDN e FDA dos genótipos de capim-elefante, referentes aos três ciclos de pastejo, encontram-se na Tabela 2. Maiores $(\mathrm{P}<0,05)$ teores de FDN foram constatados nos genótipos CNPGL 91-11-2, CNPGL 91-02-5, CNPGL 91-17-5, CNPGL 91-02-1 e CNPGL 91-19-1, com valores de 70,59; 70,$22 ; 69,48 ; 69,41$ e $69,04 \%$, respectivamente. Enquanto os menores $(\mathrm{P}<0,05)$ teores médios de FDN foram observados para os genótipos CNPGL 91-13-2, CNPGL 91-06-3, CNPGL 91-27-5, TAIWAN A-146, CNPGL 91-28-1, CNPGL 91-34-1, Mineiro, CNPGL 91-27-1, CNPGL 91-25-3, CNPGL 91-01-2, CNPGL 91-10-5 e CNPGL 91-10-2, com valores de 68,61; 68,$49 ; 68,39 ; 68,24 ; 68,20 ; 68,14 ; 67,96 ; 67,89 ; 67,71$; 67,$86 ; 67,61$; e 66,53\%, respectivamente. Os meno-
Tabela 2 - Teores médios de proteína bruta (PB), fibra em detergente neutro (FDN), fibra em detergente ácido (FDA) na base da matéria seca, dos 17 genótipos de capim-elefante (clones e cultivares), média de três ciclos de pastejo, na época das águas

Table 2 - Average contents of crude protein (CP), neutral detergent fiber (NDF), acid detergent fiber (ADF) in dry matter basis, from the 17 genotypes of elephantgrass (clones and cultivars), average of three grazing periods during the rainy season

\begin{tabular}{lccc}
\hline $\begin{array}{l}\text { Genótipos } \\
\text { Genotypes }\end{array}$ & $\begin{array}{c}\text { PB } \\
\text { CP }\end{array}$ & $\begin{array}{c}\text { FDN } \\
N D F \\
(\%)\end{array}$ & $\begin{array}{c}\text { FDA } \\
A D F\end{array}$ \\
\hline CNPGL91-19-1 & $10,52^{\mathrm{B}}$ & $69,04^{\mathrm{A}}$ & $35,09^{\mathrm{A}}$ \\
CNPGL91-10-5 & $11,22^{\mathrm{A}}$ & $67,61^{\mathrm{B}}$ & $33,95^{\mathrm{B}}$ \\
CNPGL91-27-5 & $11,23^{\mathrm{A}}$ & $68,39^{\mathrm{B}}$ & $34,33^{\mathrm{B}}$ \\
CNPGL91-02-5 & $9,40^{\mathrm{B}}$ & $70,22^{\mathrm{A}}$ & $35,65^{\mathrm{A}}$ \\
CNPGL91-01-2 & $11,64^{\mathrm{A}}$ & $67,86^{\mathrm{B}}$ & $34,18^{\mathrm{B}}$ \\
CNPGL91-13-2 & $10,15^{\mathrm{B}}$ & $68,61^{\mathrm{B}}$ & $35,38^{\mathrm{A}}$ \\
CNPGL91-25-3 & $11,26^{\mathrm{A}}$ & $67,71^{\mathrm{B}}$ & $34,71^{\mathrm{B}}$ \\
CNPGL91-10-2 & $11,34^{\mathrm{A}}$ & $66,53^{\mathrm{B}}$ & $33,55^{\mathrm{B}}$ \\
CNPGL91-02-1 & $10,76^{\mathrm{B}}$ & $69,41^{\mathrm{A}}$ & $35,06^{\mathrm{A}}$ \\
CNPGL91-11-2 & $10,19^{\mathrm{B}}$ & $70,59^{\mathrm{A}}$ & $36,32^{\mathrm{A}}$ \\
CNPGL91-34-1 & $9,79^{\mathrm{B}}$ & $68,14^{\mathrm{B}}$ & $36,19^{\mathrm{A}}$ \\
CNPGL91-27-1 & $10,51^{\mathrm{B}}$ & $67,89^{\mathrm{B}}$ & $34,23^{\mathrm{B}}$ \\
CNPGL91-28-1 & $10,56^{\mathrm{B}}$ & $68,20^{\mathrm{B}}$ & $34,51^{\mathrm{B}}$ \\
CNPGL91-06-3 & $10,48^{\mathrm{B}}$ & $68,49^{\mathrm{B}}$ & $34,87^{\mathrm{B}}$ \\
CNPGL91-17-5 & $10,08^{\mathrm{B}}$ & $69,48^{\mathrm{A}}$ & $34,72^{\mathrm{B}}$ \\
MINEIRO & $11,36^{\mathrm{A}}$ & $67,96^{\mathrm{B}}$ & $34,36^{\mathrm{B}}$ \\
TAIWAN A -146 & $10,43^{\mathrm{B}}$ & $68,24^{\mathrm{B}}$ & $35,20^{\mathrm{A}}$ \\
\hline
\end{tabular}

* Médias seguidas das mesmas letras não diferem entre si, segundo o teste de Scott-Knott $(P<0,05)$.

* Means followed by the same letters do not differ, by Scott-Knott test $(P<.05)$.

res teores de FDN, observados nos genótipos de capim-elefante, apresentaram valor médio de 67,97 $\pm 2,43 \%$, situando-se próximo aos valores citados na literatura, uma vez que baixos valores de FDN permitem o consumo de forragem de melhor qualidade.

Com relação aos teores de FDA, foram observadas diferenças $(\mathrm{P}<0,05)$ entre os genótipos de capimelefante, com os maiores teores de FDA para os genótipos CNPGL 91-11-2, CNPGL 91-34-1, CNPGL 91-02-5, CNPGL 91-13-2, TAIWAN A-146, CNPGL 91-19-1 e CNPGL 91-02-1, com os respectivos valores médios de 36,$32 ; 36,19 ; 35,65 ; 35,38 ; 35,20 ; 35,09$ e 35,06\%. Os menores valores de FDA foram observados nos genótipos CNPGL 91-06-3, CNPGL 91-17-5, CNPGL 91-25-3, CNPGL 91-28-1, Mineiro, CNPGL 91-27-5, CNPGL 91-27-1, CNPGL 91-01-2, CNPGL 91-10-5 e CNPGL 91-10-2, respectivamente, de 34,87; 34,$72 ; 34,71 ; 34,51 ; 34,36 ; 34,33 ; 34,23 ; 34,18 ; 33,95$ e $33,55 \%$. A média dos menores valores de FDA para os genótipos de capim-elefante foi de $34,34 \pm 1,70 \%$. 
Tabela 3 - Teores médios de proteína bruta $(\mathrm{PB})$, fibra em detergente neutro (FDN), fibra em detergente ácido (FDA), na base da matéria seca, médias dos 17 genótipos de capim-elefante em três ciclos de pastejo, na época das águas

Table 3 - Average contents of crude protein (CP), neutral fiber detergent (NDF), acid detergent fiber (ADF) in dry matter basis, average of 17 genotypes of elephantgrass in three grazing periods, during the rainy season

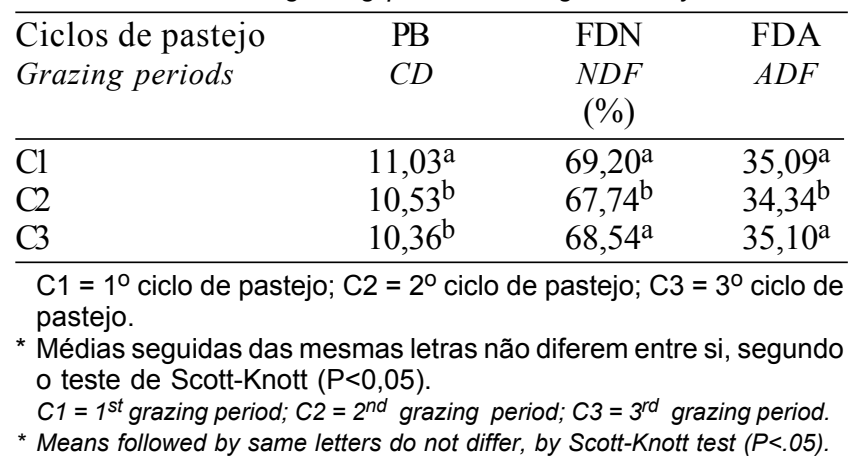

Na Tabela 3 observa-se que houve diferenças $(\mathrm{P}<0,05)$ nos teores de FDN e FDA entre os ciclos de pastejo. Durante o desenvolvimento do capim-elefante, nos intervalos de pastejo, ocorre o desenvolvimento dos perfilhos, com subseqüente aumento da relação caule:folha, indicativo da queda do valor nutritivo da forragem com aumento da fração de fibra indigerível. Os teores de FDN e FDA dos genótipos de capim-elefante parecem ser extremamente influenciados por vários fatores como intervalos de corte ou ciclos de pastejo, condições climáticas, níveis de nutrientes do solo etc.

Os valores de FDN e FDA encontrados neste trabalho são consistentes com os valores observados para a maioria das forrageiras tropicais por Reid et al. (1988). Segundo Van Soest (1967), citado por Silva (1990), valores de parede celular acima de 60\% têm correlação negativa com o consumo de MS. Lavezzo et al. (1985), trabalhando com as cultivares Roxo, Mineiro e Vruckwona em Botucatu (SP), submetidas a seis cortes com intervalos de 60 dias, encontraram valores de $61 \%$ de FDN e $35,31 \%$ de FDA para a cv. Roxo e 66,89\% de FDN e 38,26\% para a cv. Mineiro. Derez (1994), em Coronel Pacheco (MG), relatou valores de FDN de 68,5; 68,8 e 68,2\% em amostras de capim-elefante cv. Napier simulando pastejo, observados, respectivamente, em 30; 37,5 e 45 dias de descanso, na época das águas. Silva (1993), em Viçosa (MG), avaliou o efeito de três pressões de pastejo (baixa, média e alta) sobre o valor nutritivo do capim-elefante cv. Mott e encontrou maiores $(\mathrm{P}<0,05)$ teores de FDN $(69,2 \%)$ e FDA $(40,6 \%)$ em piquetes sob baixa pressão de pastejo.

A disponibilidade diferiu entre os três ciclos de pastejo $(\mathrm{P}<0,05)$, registrando-se valor mais elevado de 5,45 t de MS/ha no primeiro ciclo, conforme mostra a Figura 1. A queda na disponibilidade de forragem no segundo e terceiro ciclos de pastejo deveu-se, provavelmente, à eliminação do meristema apical, no primeiro ciclo, resultando numa rebrota lenta das gemas axilares, com alongamento insuficiente de caules, mesmo em condições climáticas consideradas ótimas para o crescimento da cultura. É amplamente aceito que a correlação entre o crescimento da pastagem e a intensidade de desfolha devese a efeitos na quantidade da forragem acumulada (residual) a cada pastejo (Humpreys, 1981). Segundo Ludlow \& Charles-Edwards (1980), a rebrota e o acúmulo de MS de gramíneas tropicais têm correlação positiva com o índice de área foliar residual e a interceptação da luz pela folhagem. Entretanto, outros fatores externos como as condições do ambiente, compactação do solo pelo pastejo, redução da fertilidade e umidade do solo poderiam ser responsáveis pela queda na disponibilidade de forragem.

Silva (1993), em avaliações da disponibilidade de matéria verde seca (MVS) de capim-elefante cv.

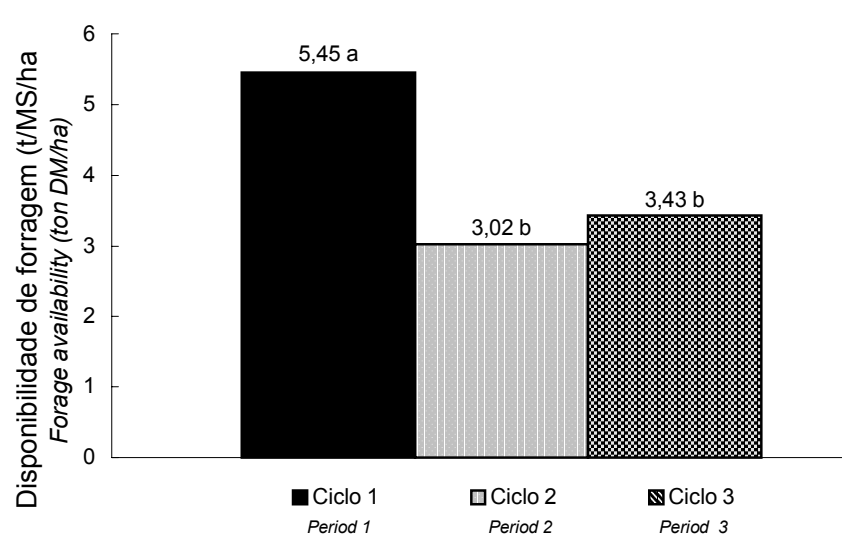

Figura 1 - Efeito do ciclo de pastejo sobre a disponibilidade de forragem (t de MS/ha) dos genótipos de capimelefante. Médias seguidas das mesmas letras não diferem entre si, segundo o teste de ScottKnott $(P<0,05)$.

Figure 1 - Effect of grazing period on the availability forage (t $D M / h a)$ of the elephantgrass genotypes. *Means followed by the same letters do not differ, by Scott-Knott test $(P<.05)$. 
Mott, coletou amostras por estrato acima de $0,80 \mathrm{~m}$, de 0,60 a $0,80 \mathrm{~m}$, de 0,40 a $0,60 \mathrm{~m}$ e de 0,20 a $0,40 \mathrm{~m}$ sob três pressões de pastejo (alta, média e baixa) e observou o aumento da MVS em piquetes com extratos de forragem superiores e pressão de pastejo alta, cerca de 7,75 t de MS/ha. Isto poderia ser explicado pela diminuição do caule e pseudo-caule acumulados, pois esses são praticamente nulos sob pressão de pastejo alta. Veiga (1994) relatou produção de MS de capim-elefante cv. Mott na Flórida-USA, da ordem de 6,98 t de MS/ha, em ciclos de pastejo com 28 dias de descanso e pressão de pastejo baixa. Townsend et al. (1994), avaliando quatro diferentes cultivares de capim-elefante sob condições de pastejo, em três ciclos de pastejo, na época das águas, no Rio Grande do Sul, não constataram diferenças $(\mathrm{P}>0,05)$ na disponibilidade de MS entre as cultivares, com médias oscilando entre 9,54 t/ha (cv. Porto Rico) e 6,81 t/ha (cv. Cameroon). No entanto, observaram diferenças entre as médias de disponibilidade de MS dos ciclos de pastejo.

Não foram observadas diferenças $(P>0,05)$ na disponibilidade de forragem entre os genótipos neste experimento, cuja média geral foi de 3,97 $\pm 2,82 \mathrm{t}$ de MS/ha. Os valores médios da PMS estão apresentados na Tabela 4. Daher et al. (1997), avaliando a competição de diferentes genótipos de capim-elefante em regime de corte em Campos dos Goytacazes, RJ,

Tabela 4 - Disponibilidade de forragem de 17 genótipos de capim-elefante, média de três ciclos de pastejo, de acordo com a produção de matéria seca (PMS) acima de 0,80 $\mathrm{m}$ do solo, durante a época das águas

Table 4 - Forage availability of 17 genotypes of elephantgrass, average of three grazing periods, according to the dry matter yield (DMY) up $80 \mathrm{~cm}$ above ground, during the rainy season

\begin{tabular}{lccc}
\hline $\begin{array}{l}\text { Genótipos } \\
\text { Genotypes }\end{array}$ & $\begin{array}{c}\text { PMS (t/ha })^{1} \\
D M Y(t / h a)^{1}\end{array}$ & $\begin{array}{c}\text { Genótipos } \\
\text { Genotypes }\end{array}$ & $\begin{array}{c}\text { PMS (t/ha })^{1} \\
\text { DMY }(\mathrm{t} / \mathrm{ha})^{1}\end{array}$ \\
\hline CNPGL91-19-1 & 4,28 & CNPGL91-11-2 & 3,28 \\
CNPGL91-10-5 & 3,23 & CNPGL91-34-1 & 4,29 \\
CNPGL91-27-5 & 3,67 & CNPGL91-27-1 & 4,08 \\
CNPGL91-02-5 & 3,55 & CNPGL91-28-1 & 5,06 \\
CNPGL91-01-2 & 4,50 & CNPGL91-06-3 & 5,38 \\
CNPGL91-13-2 & 2,86 & CNPGL91-17-5 & 4,43 \\
CNPGL91-25-3 & 4,09 & MINEIRO & 3,85 \\
CNPGL91-10-2 & 3,92 & TAIWANA-146 & 4,07 \\
CNPGL91-02-4 & 2,88 & & \\
\hline \multicolumn{5}{c}{ Média } \\
\hline
\end{tabular}

${ }_{1}^{1}$ As médias não diferem pelo teste de Scott-Knott $(P<0,05)$.

${ }^{1}$ Means do not differ, by Scott-Knott test $(P<.05)$.

R. Bras. Zootec., v.31, n.1, p.313-320, 2002 (suplemento) encontraram diferenças $(\mathrm{P}<0,05)$ nos valores de produção de MS, registrando valores médios variando de 3480 a $6862 \mathrm{~kg} / \mathrm{ha} /$ corte, em seis cortes. Canto et al. (1974), avaliando a altura de corte do capim-elefante sobre a produção de MS em cinco cortes (três no período chuvoso e dois no período seco), observaram rendimento de forragem de até $5362 \mathrm{~kg}$ de MS/ha/ corte, com altura de corte de $25 \mathrm{~cm}$. Segundo Corsi (1992), o aumento da PMS do capim-elefante sob regime de cortes é extremamente favorecido com alturas de corte entre 20 e $35 \mathrm{~cm}$, em intervalos de corte de 45 a 50 dias, pela eliminação dos meristemas apicais dos perfilhos basais. Este autor ressaltou que, no entanto, a produção de MS sob regime de pastejo pode ser afetada pela altura elevada de pastejo e pela não-eliminação dos meristemas apicais, ocorrendo acúmulo excessivo de material morto, o qual limita (pelo sombreamento) o perfilhamento basal no início da estação de crescimento.

O IAF dos genótipos, nos três ciclos de pastejo, foi submetido à análise de variância, sendo observada significância na interação de genótipos e ciclos de pastejo (Tabela 5). No primeiro ciclo de pastejo, os genótipos CNPGL 91-02-5 e CNPGL 91-11-2 apresentaram os maiores IAF, com valores extremos de 7,08 e 6,67 , respectivamente, quando comparados com os demais genótipos. Entretanto, o IAF desses clones nos ciclos 2 e 3 foram menores $(\mathrm{P}<0,05)$ do que o IAF do ciclo 1, indicando a variação dos valores de IAF de acordo com a época de pastejo, como observado na Tabela 5. Assim como a PMS do capimelefante, o IAF deve ter sido favorecido por uma melhor formação inicial das parcelas e também pelas boas condições ambientais no primeiro ciclo de pastejo.

Queiroz (1982) observou IAF para o capimjaraguá [Hyparrhenia rufa (Nees) Stapf.] variando de 1,9 a 3,0 e de 5,3 a 10,8 , respectivamente, na ausência e presença de adubação nitrogenada. Segundo Gomide (1973), alguns fatores ambientais tais como a radiação incidente sobre a cultura, os níveis de fertilidade e umidade do solo influenciam diretamente o IAF. Os valores de IAF máximos encontrados neste experimento foram superiores aos relatados por Alcântara et al. (1991) para cultivares de Panicum maximum Jacq. que variaram de 5,0 a 6,7. O mesmo é constatado quando é citado o trabalho de Paciullo et al. (1996), avaliando algumas características morfofisiológicas do capim-elefante cv. Mott sob diferentes doses de $\mathrm{N}$, que encontraram um IAF máximo de 4,5, aplicando $100 \mathrm{~kg} \mathrm{~N} /$ ha a cada corte. 
Tabela 5 - Valores médios de IAF total dos 17 genótipos de capim-elefante, observados em três ciclos de pastejo, durante a época das águas

Table 5 - Average values of overall LAl of the 17 genotypes of elephantgrass, remarked in three grazing periods, during the rainy season

\begin{tabular}{lcccc}
\hline Genótipos & $\begin{array}{c}\text { Ciclo 1 } \\
\text { Period 1 }\end{array}$ & $\begin{array}{c}\text { Ciclo 2 } \\
\text { Period 2 }\end{array}$ & $\begin{array}{c}\text { Ciclo 3 } \\
\text { Period 3 }\end{array}$ & $\begin{array}{c}\text { Média } \\
\text { Mean }\end{array}$ \\
\hline CNPGL91-19-1 & $4,29^{\mathrm{Ca}}$ & $3,19^{\mathrm{Aa}}$ & $3,33^{\mathrm{Aa}}$ & $3,60^{\mathrm{A}}$ \\
CNPGL91-10-5 & $2,39^{\mathrm{Ca}}$ & $2,26^{\mathrm{Aa}}$ & $1,57^{\mathrm{Ba}}$ & $2,08^{\mathrm{B}}$ \\
CNPGL91-27-5 & $4,06^{\mathrm{Ca}}$ & $1,98^{\mathrm{Ab}}$ & $1,71^{\mathrm{Bb}}$ & $2,58^{\mathrm{B}}$ \\
CNPGL91-02-5 & $7,08^{\mathrm{Aa}}$ & $2,64^{\mathrm{Ab}}$ & $3,81^{\mathrm{Ab}}$ & $4,51^{\mathrm{A}}$ \\
CNPGL91-01-2 & $4,38^{\mathrm{Ca}}$ & $1,55^{\mathrm{Ab}}$ & $2,37^{\mathrm{Bb}}$ & $2,77^{\mathrm{B}}$ \\
CNPGL91-13-2 & $5,68^{\mathrm{Ba}}$ & $2,20^{\mathrm{Ab}}$ & $2,97^{\mathrm{Ab}}$ & $3,62^{\mathrm{A}}$ \\
CNPGL91-25-3 & $4,15^{\mathrm{Ca}}$ & $2,66^{\mathrm{Aa}}$ & $3,96^{\mathrm{Aa}}$ & $3,59^{\mathrm{A}}$ \\
CNPGL91-10-2 & $3,33^{\mathrm{Ca}}$ & $2,30^{\mathrm{Aa}}$ & $1,60^{\mathrm{Ba}}$ & $2,41^{\mathrm{B}}$ \\
CNPGL91-02-1 & $5,38^{\mathrm{Ba}}$ & $1,90^{\mathrm{Ab}}$ & $2,36^{\mathrm{Bb}}$ & $3,21^{\mathrm{A}}$ \\
CNPGL91-11-2 & $6,67^{\mathrm{Aa}}$ & $2,59^{\mathrm{Ab}}$ & $3,33^{\mathrm{Ab}}$ & $4,20^{\mathrm{A}}$ \\
CNPGL91-34-1 & $4,25^{\mathrm{Ca}}$ & $4,06^{\mathrm{Aa}}$ & $3,00^{\mathrm{Aa}}$ & $3,77^{\mathrm{A}}$ \\
CNPGL91-27-1 & $3,85^{\mathrm{Ca}}$ & $1,92^{\mathrm{Ab}}$ & $1,83^{\mathrm{Bb}}$ & $2,53^{\mathrm{B}}$ \\
CNPGL91-28-1 & $4,74^{\mathrm{Ca}}$ & $2,81^{\mathrm{Ab}}$ & $2,79^{\mathrm{Ab}}$ & $3,45^{\mathrm{A}}$ \\
CNPGL91-06-3 & $4,73^{\mathrm{Ca}}$ & $2,33^{\mathrm{Ab}}$ & $2,65^{\mathrm{Bb}}$ & $3,24^{\mathrm{A}}$ \\
CNPGL91-17-5 & $5,20^{\mathrm{Ba}}$ & $1,71^{\mathrm{Ab}}$ & $4,42^{\mathrm{Aa}}$ & $3,77^{\mathrm{A}}$ \\
MINEIRO & $3,55^{\mathrm{Ca}}$ & $1,87^{\mathrm{Ab}}$ & $2,17^{\mathrm{Bb}}$ & $2,53^{\mathrm{B}}$ \\
TAIWAN A -146 & $4,43^{\mathrm{Ca}}$ & $2,64^{\mathrm{Ab}}$ & $1,92^{\mathrm{Bb}}$ & $2,99^{\mathrm{B}}$ \\
\hline Média & $4,60^{\mathrm{a}}$ & $2,39^{\mathrm{b}}$ & $2,69^{\mathrm{b}}$ & - \\
Mean & & & & \\
\hline
\end{tabular}

* Médias seguidas das mesmas letras maiúsculas na coluna e minúsculas na linha não diferem entre si, segundo o teste de Scott-Knott $(P<0,05)$.

* Means followed by the same capital letters in the column and tiny in the row do not differ, by Scott-Knott test $(P<.05)$

Em pastagem de Brachiaria decumbens Stapf., Gomide et al. (1997) observaram valores de IAF variando de 3,3 a 6,9 com altura do relvado de 10 a $40 \mathrm{~cm}$, respectivamente. De acordo com os resultados observados na literatura, os valores de IAF encontrados neste experimento também parecem ser influenciados por condições ambientais e de manejo adequadas, uma vez que níveis ótimos de adubação e o pastejo rotativo (com tecido foliar remanescente) favorecem o processo de rebrota e acumulação de MS.

\section{Conclusões}

Os genótipos CNPGL 91-01-2, CNPGL 91-10-2, CNPGL 91-25-3, CNPGL 91-10-5 e CNPGL 91-27-5 apresentaram maiores teores de $\mathrm{PB}$ e menores valores de FDN e FDA, tal como a cultivar Mineiro.

A composição químico-bromatológica dos genótipos foi influenciada negativamente ciclo após ciclo, pelos fatores externos de produção, como o pastejo e as condições climáticas.

R. Bras. Zootec., v.31, n.1, p.313-320, 2002 (suplemento)
Os genótipos não apresentaram diferenças $(\mathrm{P}>0,05)$ quanto à disponibilidade de forragem, que foi influenciada negativamente após cada ciclo de pastejo.

Embora tenha havido diferenças de IAF entre os genótipos, isso não resultou em diferenças na disponibilidade de forragem.

\section{Literatura Citada}

ALCÂNTARA, V.B.G.; ALMEIDA, A.R.P.; GHISI, O.M.A.A. Algumas medidas morfofisiológicas em seis cultivares de Panicum maximum. Revista Agricultura, v.66, n.1, p.47-63, 1991.

BOTREL, M.A.; ALVIM, M.J.; MARTINS, C.E. Avaliação e seleção de cultivares de capim-elefante (Pennisetum purpureum, Schum.) para pastejo. Revista da Sociedade Brasileira de Zootecnia, v.23, n.5, p.754-762. 1994.

CANTO, A.C.; TEIXEIRA, L.B.; MEDEIROS, J.C. et al. Altura do corte em capim-elefante (Pennisetum purpureum, Schum.). Seiva, v.43, n.83, p.18-25, 1974.

COSTA, N.L. Adubação nitrogenada e consorciação de capimelefante. Pesquisa Agropecuária Brasileira, v.30, n.3, p.401-408, 1995.

CORSI, M. Manejo de capim-elefante sob pastejo. In: SIMPÓSIO SOBRE MANEJO DA PASTAGEM, 10., 1992, Piracicaba. Anais... Piracicaba: Fundação de Estudos Agrários "Luiz de Queiroz", 1992. p.143-167.

DAHER, R.F.; VASQUEZ, M.H.; FERNANDES, A.M. et al. Competição de clones de capim-elefante (Pennisetum purpureum, Schum.) em Campos dos Goytacazes, RJ. In: REUNIÃO ANUAL DA SOCIEDADE BRASILEIRA DE ZOOTECNIA, 34., 1997, Juiz de Fora. Anais... Juiz de Fora: Sociedade Brasileira de Zootecnia, 1997. p.59-61.

DEREZ, F. Manejo de pastagens de capim-elefante para produção de leite e carne. In: SIMPÓSIO SOBRE CAPIM-ELEFANTE, 2., 1994, Juiz de Fora. Anais... Coronel Pacheco: editora, 1994. p.116-137.

GOMIDE, J.A. Fisiologia e manejo de plantas forrageiras. Revista da Sociedade Brasileira de Zootecnia, v.2, n.1, p.17-26, 1994.

GOMIDE, C.A.M.; GOMIDE, J.A.; QUEIROZ, D.S. Fluxo de tecidos de Brachiaria decumbens. In: REUNIÃO ANUAL DA SOCIEDADE BRASILEIRA DE ZOOTECNIA, 34., 1997, Juiz de Fora. Anais... Juiz de Fora: Sociedade Brasileira de Zootecnia, 1997. p.117-119.

HUMPHREYS, L.R. Environmental adaptation of tropical pasture plants. London: MacMillan Publishers, 1981.261p.

LAVEZZO, W.; LAVEZZO, O.E.N.M.; GARCIA, E. A. Estudo comparativo das variedades Roxo, Mineiro e Vruckwona de capim-elefante (Pennisetum purpureum, Schum.) II. Composição bromatológica pelo método tradicional e análise da fração fibrosa. In: REUNIÃO ANUAL DA SOCIEDADE BRASILEIRA DE ZOOTECNIA, 22., 1985, Camboriú. Anais... Camboriú: Sociedade Brasileira de Zootecnia, 1985. p.333.

LUDLOW, M.M.; CHARLES-EDWARDS, D.A. Analysis of regrowth of a tropical grass/legume sward subjected to different frequencies and intensities of defoliation. Australian Journal of Agricultural Research, v.31, p.673-692, 1980.

MINSON, D.J. Effects of chemical and physical composition of herbage eaten upon intake. In: HACKER, J.B. (Ed.) Nutritional limits to animal production from pasture. St. Lucia: Commonwealth Agriculture Bureaux, 1984. p.187-192. 
OLIVO, C.J.; MOREIRA, J.C.; BARRETO, I.L. et al. Utilização de pastagens de capim-elefante e capim-setária como base da alimentação de vacas em lactação, durante o verão. Revista da Sociedade Brasileira de Zootecnia, v.21, n.3, p.347-352, 1992.

OMETTO, J.C. Bioclimatologia vegetal. São Paulo: Agronômica Ceres, 1981. 440p.

PACIULlO, D.S.C.; GOMIDE, J.A.; FONSECA, D.M. Parâmetros morfofisiológicos do capim-elefante anão ao atingir duas alturas sob cinco doses de nitrogênio. In: REUNIÃO ANUAL DA SOCIEDADE BRASILEIRA DE ZOOTECNIA, 33., 1996, Fortaleza. Anais... Fortaleza: Sociedade Brasileira de Zootecnia, 1996. p.406-408,

PEREIRA, A.V.; MARTINS, C.E.; CRUZ FILHO, A.B. et al. Pioneiro - Nova cultivar de capim-elefante para pastejo. In: REUNIÃO ANUAL DA SOCIEDADE BRASILEIRA DE ZOOTECNIA, 34., 1997, Juiz de Fora. Anais... Juiz de Fora: Sociedade Brasileira de Zootecnia, 1997. p.102-104.

QUEIROZ, D.S. Efeito da freqüência de cortes, da adubação de reposição e do espaçamento sobre a produtividade e o valor nutritivo do capim-jaraguá (Hyparrhenia rufa). Viçosa, MG: Universidade Federal de Viçosa, 1982. 48p. Dissertação (Mestrado em Zootecnia) - Universidade Federal de Viçosa, 1982.

REID, R.L.; JUNG, G.A.; THAYNE, W.V. Relationships between nutritive quality and fibre components of cool season and warm season forages: a retrospective study. Journal of Animal Science, v.66, n.5, p.1275-1291, 1988.

SILVA, D.J. Análise de alimentos: métodos químicos e biológicos. 2.ed. Viçosa, MG: Universidade Federal de Viçosa, 1990. 165p.
SILVA, D.S. Efeito da pressão de pastejo sobre a estrutura, a produtividade e a persistência do capim-elefante Anão (Pennisetum purpureum, Schum., cv. Mott). Viçosa, MG: Universidade Federal de Viçosa, 1993. 88p. Tese (Doutorado em Zootecnia) - Universidade Federal de Viçosa, 1993.

TOWNSEND, C.R.; OLIVO. C.J.; RUVIARO, C.F. et al. Desempenho de novilhas da raça holandês em cultivares de capim-elefante (Pennisetum purpureum, Schum.). Ciência Rural, v.24, n.2, p.381-386, 1994.

UNIVERSIDADE FEDERAL DE VIÇOSA - UFV. SAEG Sistema para análises estatísticas e genéticas. Versão 7.1. Viçosa, MG: 1997. 150p. (Manual do usuário).

VEIGA, J.B. Utilização do capim-elefante sob pastejo. In: CARVALHO, M. M.; ALVIM, M. J., XAVIER, D. F. et al. (Eds.) Capim-elefante: produção e utilização. Coronel Pacheco: EMBRAPA-CNPGL, 1994. p.165-193.

Recebido em: 24/11/00

Aceito em: 01/10/01 